\title{
A RECORRÊNCIA DE RIMAS NO SAMBA ENREDO CARIOCA ENTRE AS DÉCADAS DE 1970 e 2010
}

The rimas recurrence in samba enredo carioca between the 1970 and 2010 decades

\author{
João Gabriel Costa de França Souza ${ }^{1}$
}

RESUMO: O carnaval carioca, enquanto representante cultural brasileiro, anualmente apresenta, como uma de suas mais importantes manifestações, o desfile das escolas de samba. Essas apresentações são verdadeiros espetáculos a céu aberto, capazes de unir elementos visuais e musicais em uma verdadeira simbiose. Destaca-se então o samba enredo, gênero musical genuinamente brasileiro e indissociavelmente ligado aos desfiles. Sua origem remonta à primeira metade do século $\mathrm{XX}$ e sua evolução é amplamente debatida e estudada, principalmente nas últimas décadas. Composto por dois fundamentais pilares, letra e melodia, iremos nos ater aos detalhes poéticos do primeiro. Dessa forma, neste trabalho analisaremos a evolução do gênero samba enredo através das décadas de 1970, 1980, 1990, 2000 e 2010, sob a ótica da recorrência de rimas nas letras de suas composições.

Palavras-chave: Samba. Carnaval. Rima. Música. Cultura.

ABSTRACT: Carnival in Rio, as a Brazilian cultural representative, annually presents, as one of its most important manifestations, the parade of samba schools. These presentations are real open air shows, capable of bringing together visual and musical elements in a true symbiosis. The samba enredo stands out, a genuinely Brazilian musical genre and inextricably linked to the parades. Its origin dates back to the first half of the zoth century and its evolution is widely debated and studied, mainly in the last decades. Composed of two fundamental pillars, lyrics and melody, we will stick to the poetic details of the first one. Thus, in this work we will analyze the evolution of the samba enredo genre through the 1970s, I980s, I990s, 2000s and 2010s, under the optics of rhyme recurrence in the lyrics of their compositions.

Keywords: Samba. Carnival. Rhymet. Music. Culture.

\section{INTRODUÇÃO}

O samba enredo, gênero musical genuinamente brasileiro, caracteriza-se por mesclar elementos narrativos e líricos em sua construção poética (FERRARI, 2017, p. 13). A narrativa, de tom predominantemente épico, possui a função de aliada à parte plástica, introduzir e desenvolver o tema

\footnotetext{
${ }^{1}$ Licenciado em física pela Universidade Federal do Rio de Janeiro (UFRJ), atua desde 2016 na pesquisa dos carnavais Carioca e Niteroiense. Possui três livros lançados sobre essa temática: Carnaval de Niterói - O resgate das memórias esquecidas (2016); Entre o asfalto e a passarela: O olhar carnavalesco de Clóvis Bornay (2020); E do samba fez história (2020). É também compositor de samba enredo, com passagens pelo grupo especial de São Paulo e pelos grupos de acesso do Rio de Janeiro, Vitória e Passo Fundo.
} 
enredo apresentado pela escola de samba em seus desfiles, ao passo que ao lirismo relaciona-se a poesia e a assimilação musical da obra por parte de desfilantes e do público. A evolução dos modelos de apresentação carnavalescas e seus julgamentos refletiram diretamente nos aspectos poéticos, rítmicos e melódicos dos sambas de enredo com o passar das décadas.

Nos primeiros anos de concurso (década de 1930) as escolas de samba apresentavam-se com sambas já consagrados em suas comunidades, geralmente bastante curtos, que possibilitassem o improviso entre seus estribilhos. Para efeitos de julgamento, esses sambas não necessitavam de qualquer conexão com o tema desenvolvido pela agremiação. Foi apenas na década de I950, especificamente em 1952, que o Regulamento dos desfiles das escolas de samba do Rio de Janeiro determinou claramente a obrigatoriedade do intercâmbio entre a letra do samba apresentado e o enredo desenvolvido na avenida (RIOTUR, p. 322).

Outros aspectos regulamentares também influenciaram a evolução do gênero. A diminuição do tempo de desfiles ao longo dos anos, aliada ao grande crescimento de contingente de desfilantes, levaram à tendência de confecção e execução aceleradas dos sambas, fato que se refletiu diretamente nas melodias e na métrica dos mesmos (PRADO, 2015, p. 168).

Até mesmo a massificação das composições, viabilizada pelas gravações em long play (a partir de 1968), devido ao rigoroso limite de tempo das faixas e a reprodução nas rádios, culminou em mudanças estruturais no gênero, como a redução do número de versos e aumento do andamento (HENRIQUE, 2008, p. 62).

Aliado a esses processos, a evolução dos critérios de julgamento dos desfiles também influenciou a estruturação rítmica, poética e melódica do gênero. O Manual do Julgador, espécie de livro de diretrizes fornecido aos jurados dos desfiles oficiais do Grupo Especial pela Liga Independente das Escolas de Samba do Rio de Janeiro (LIESA), orienta a avaliação do quesito samba enredo sob duas óticas: letra e melodia. O primeiro deve ser julgado quanto à sua adequação ao enredo, riqueza poética, beleza, bom gosto e adaptação à melodia. Já o segundo é avaliado em relação às características rítmicas, riqueza melódica, beleza, bom gosto e viabilidade harmônica de facilitar o canto e a dança dos desfilantes (LIESA, 2020, p. 43). É perceptível a subjetividade com a qual os julgamentos se desenvolvem, diversas vezes culminando em notas justificadas por fatores técnicos que se afastam do âmago popular do gênero, como concordâncias e repetições de rimas.

Outros quesitos também atuaram diretamente no processo evolutivo do samba enredo. As instruções para os jurados encontradas no Manual do Julgador orientam a avaliação de harmonia, entre outros fatores, segundo a harmonia do samba e o canto da obra de maneira uníssona pelos 
desfilantes (LIESA, 2020, p. 44). A adaptação a esses critérios acarretou "uma grande preocupação com construções fáceis de serem memorizadas, enfatizando o verso rimado na constituição do ritmo, da sonoridade das frases cantadas." (FARIAS, 2008, p. 76).

Esse fenômeno conduziu os compositores à busca por estruturas de simples assimilação, como, por exemplo, refrões de pergunta e resposta e padrões facilmente reconhecíveis de conjuntos de vocábulos e rimas (PRADO, 2015, p. 159).

Em respeito também às narrativas de enredo, o quesito homônimo influenciou diretamente a composição, uma vez que os sambas cada vez mais se entrelaçaram às sinopses, culminando em um engessamento da liberdade poética do compositor.

A evolução do gênero levou a discussões a respeito da qualidade das obras com o passar dos anos. O saudosismo, intrínseco ao mundo do carnaval, leva inevitavelmente às comparações entre composições de diferentes décadas. É inegável a mutação, porém altamente subjetiva a noção de piora ou melhorará de qualidade. Considerando o samba enredo como um produto final único composto de dois elementos fundamentais (letra e melodia), iremos neste estudo nos ater ao primeiro. Especificamente no tocante à ocorrência de rimas nas obras apresentadas pelas escolas de samba em seus desfiles entre os anos de 1968 e 2020. Em tese, em decorrência dos fatores supracitados, esperase que os dados analisados indiquem aumento da quantidade de rimas através das décadas.

Compreender o processo de evolução do aparecimento de rimas como recursos poéticos, musicais, descritivos e estilísticos poderá nos colocar mais próximos do entendimento acerca das modificações observadas no gênero samba enredo através dos últimos carnavais.

\section{DADOS E MÉTODO}

Através da análise das letras dos sambas enredo apresentados pelas escolas de samba do Grupo Especial do Rio de Janeiro entre os anos de 1968 e 2020, fez-se possível traçar padrões de recorrência de rimas e palavras-chave através das décadas de 1970, 1980, 1990, 2000 e 2010.

As rimas foram divididas em três grupos: pobres, ricas e totais. Por definição, foram catalogadas como rimas totais as palavras que possuem semelhança de sons que se acoplam (PIGNATARI, 2005, p. 37). As demais rimas devem obedecer ao mesmo critério, subdividindo-se entre palavras de mesma classe gramatical (pobres) ou de classes gramaticais diferentes (ricas).

Um universo de 683 sambas foi analisado, excetuando-se sambas reeditados, adaptações de outros gêneros da Música Popular Brasileira ao samba enredo e, especificamente, o samba da Unidos 
de Vila Isabel de 1987, por ser propositalmente construído sem rimas (DA VILA; BESSA; AZO, 1986).

Após subdivididas, as rimas foram catalogadas sem distinção quanto à igualdade ortográfica e sonoridade ou quanto a suas posições nos versos e agrupadas por década. Palavras que se repetem, recurso bastante utilizado pelos compositores do gênero, somente foram contabilizadas quanto, apesar de ortograficamente idênticas, apresentaram classes gramaticais distintas. Sequências de dois ou mais vocábulos que apresentassem rimas foram analisadas aos pares, de maneira a respeitar a cronologia de seus aparecimentos na letra.

Ao passo que a quantidade de versos nas obras não se mostra constante no período estudado (decresce até metade da década de 1970 e volta a crescer até o final da década de 2010), a recorrência de rimas como valor absoluto não seria de grande valor estatístico. Portanto, os valores finais para análise foram considerados, ano a ano, a razão entre a quantidade de rimas (fossem pobres, ricas ou totais) e a quantidade total de versos, avaliada diretamente dos encartes de long plays e CDs. A essa razão denominamos fator de comparação e sobre ela consiste na análise.

Para efeitos de comparação, estudou-se paralelamente os sambas vencedores do prêmio Estandarte de Ouro, entre os anos de 1972 e 2020, excetuando-se 2004, a fim de compreendermos se seus fatores de comparação encontram-se ou não acima da média das demais composições apresentadas no mesmo ano.

Por fim, foi realizado um levantamento do vocábulo mais utilizado em rimas em todo o intervalo cronológico, levando em consideração apenas substantivos, adjetivos, verbos, advérbios e pronomes, a fim de verificar a recorrência de termos ou rimas específicas.

\section{RESULTADOS}

Dos 683 sambas enredo analisados no período, em um total de 97.914 palavras, observou-se consistência de crescimento linear em todos os subgrupos de rimas abordados.

No caso das rimas pobres catalogadas, o crescimento do fator de comparação foi em média de 0,0225 rimas/verso a cada década, com um aumento total de aproximadamente 39,13\% no período.

Por sua vez, as rimas ricas apresentaram crescimento percentual mais elevado no período, variando em média o,035 rimas/verso a cada década, um crescimento médio 55,56\% maior se comparado ao de rimas pobres. Por conseguinte, no período estudado o crescimento de rimas ricas por verso foi de $140 \%$, o maior percentual dentre os grupos abordados. 
Gráfico I - Fator de Comparação nas ocorrências de rimas pobres ao longo das décadas abordadas no estudo

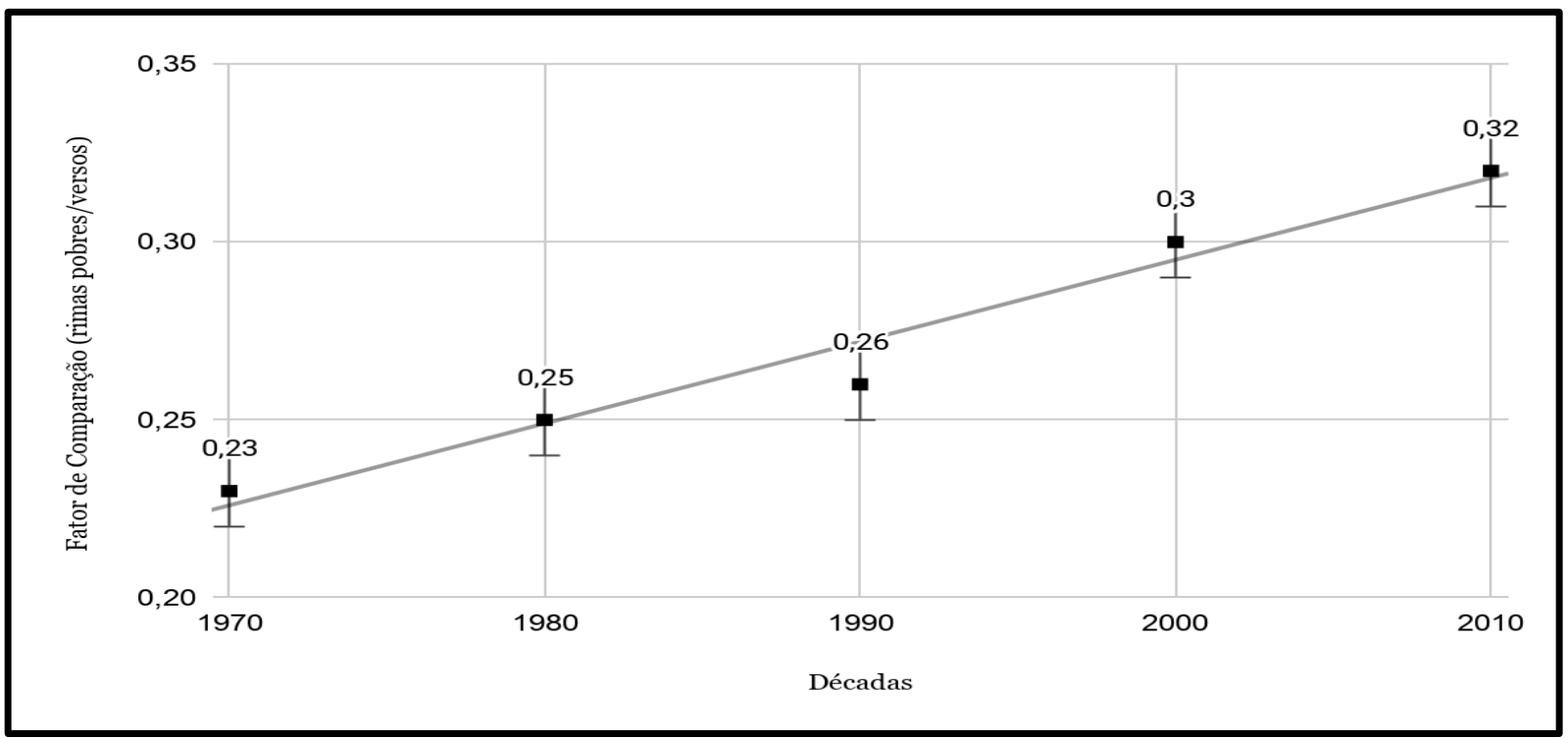

Fonte: Elaborado pelo autor (2021)

Gráfico 2 - Fator de Comparação nas ocorrências de rimas ricas ao longo das décadas abordadas no estudo

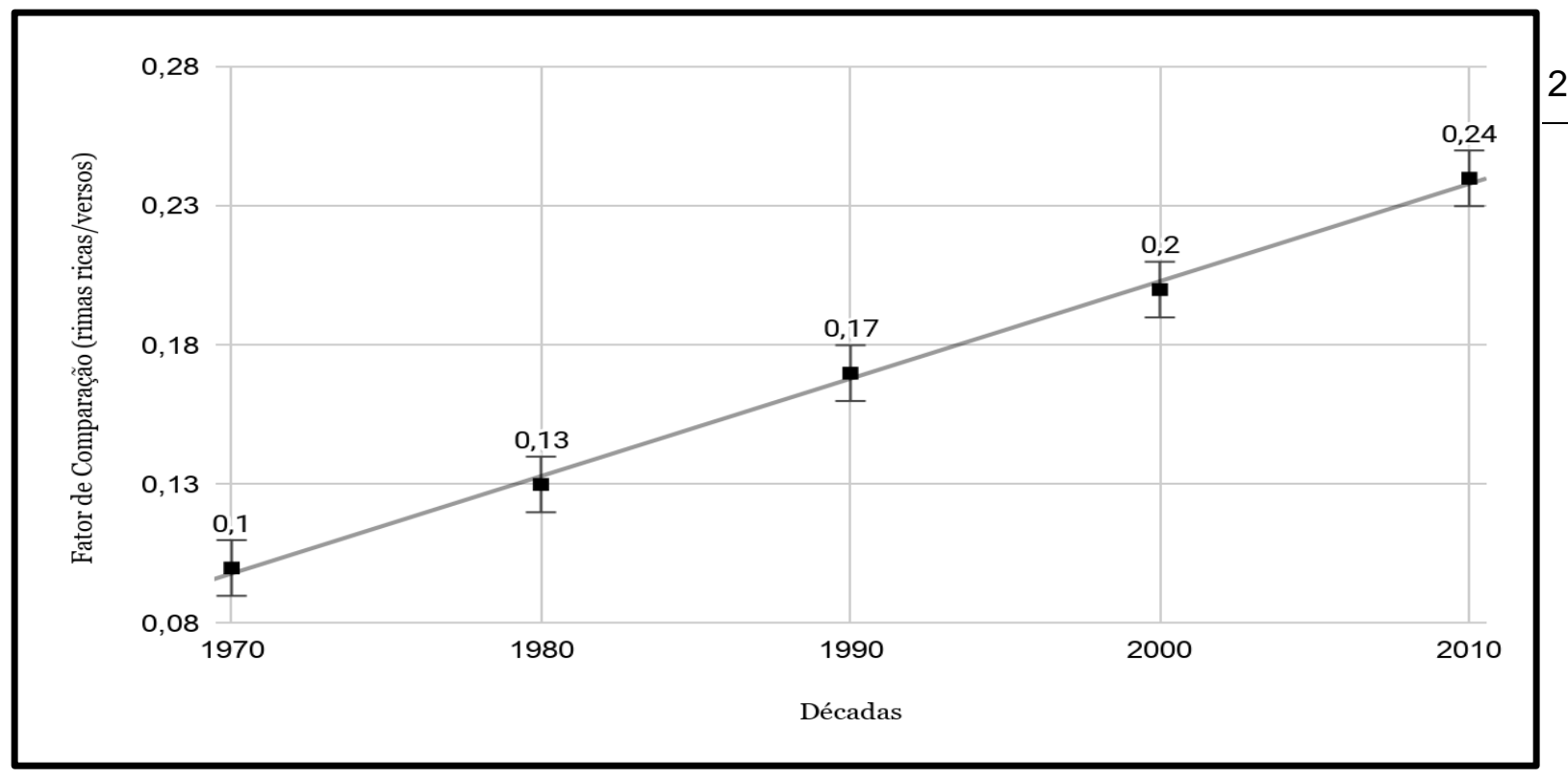

Fonte: Elaborado pelo autor (2021)

Em adição, ao analisarmos o aspecto geral de aumento nas rimas totais, nos deparamos com um crescimento igualmente importante do ponto de vista da construção poética das composições. A 
cada década observou-se um crescimento médio de o,055 rimas/verso e no panorama geral um crescimento de $64,7 \%$ do total de rimas por verso no período.

Gráfico 3 - Fator de Comparação nas ocorrências de rimas totais ao longo das décadas abordadas no estudo

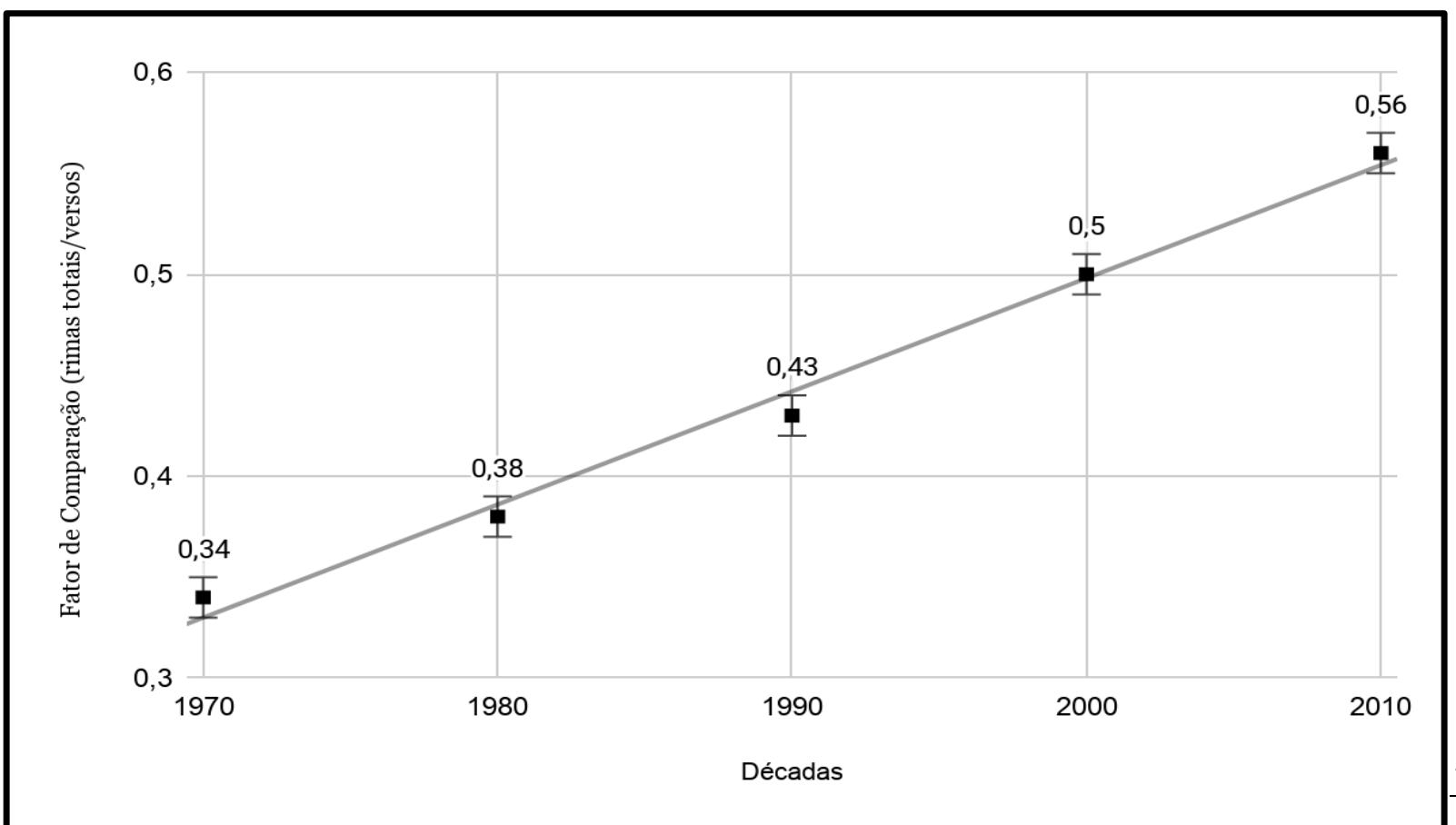

Fonte: Elaborado pelo autor (2021)

Por sua vez, os sambas enredo premiados com o Estandarte de Ouro, honraria concedida anualmente pelo Jornal O Globo aos melhores do carnaval carioca em suas respectivas categorias, possuem em média mais rimas que os demais sambas do mesmo ano. Do total analisado (1972 a 2020, exceto o ano de 2004, no qual a premiação foi concedida a um samba reeditado), as composições premiadas apresentaram maior ou igual ocorrência de rimas pobres, se comparadas com a média anual, em 34 anos de um total de 48 (70,83\%). Quanto às rimas ricas, a supremacia também se manteve em 39 anos do mesmo total (81,25\%).

Dentre os vocábulos mais rimados, chamam atenção: Carnaval (28I ocorrências) e Samba (288 ocorrências), substantivos bastante recorrentes, uma vez que são a tônica da concepção e construção do gênero em seu âmago. A palavra Brasil (324 ocorrências), ou mesmo brasileiro (8o 
ocorrências), se repete um alto número de vezes, muito em função das temáticas nacionais e ufanistas ainda bastante presentes no carnaval carioca.

Dentre todos os vocábulos analisados, um em especial chama atenção. A palavra 'amor' aparece em 575 oportunidades. Se observamos algumas variações da mesma palavra que mantêm o mesmo significado, como 'amores', chegamos à marca de 599 ocorrências. Se levarmos em consideração os 683 sambas analisados, a média de ocorrência do vocábulo é de o,88 aparições por samba, nos levando a deduzir que a maior parte dos compositores do período em questão utilizou esta palavra em suas obras. Comparando percentualmente, 'amor' representa o,61\% do total de palavras utilizadas em todos os sambas enredo do período, ao passo que, combinados, 'carnaval' e 'samba' alcançaram a marca de $0,58 \%$.

\section{Discussão}

Não é possível traçarmos um paralelo direto entre quantidade de rimas, sejam pobres, ricas, raras ou de quaisquer outros tipos, e qualidade dos sambas enredo. Diversas vezes o compositor busca saídas, sejam poéticas, de narrativa ou melódicas, em palavras que rimam e sejam capazes de produzir um entendimento sonoro mais direto e agradável ao ouvinte. Não raramente a necessidade sonora suplanta o rigor semântico, técnico ou de significação dos versos.

$\mathrm{Na}$ escolha dos vocábulos é determinante também a necessidade de rima e de metro e o efeito sonoro das palavras em relação com a melodia. Num comportamento linguístico próprio da poesia, a preocupação com o significante é maior do que na comunicação predominantemente denotativa (VALENÇA, 1983, p. I02).

A palavra bonita, sonora e imponente tem para ele [o compositor] mais valor do que outra que se encaixe melhor no contexto semântico, mas que não ofereça os mesmos recursos de rima e de simples sonoridade. Esse comportamento linguístico não é privilégio do compositor de samba enredo; em geral, todo poeta popular vê nas palavras mais a camada fônica e sonora, muitas vezes em detrimento da camada do significado (VALENÇA, 1983, p. 137).

Tal fenômeno traduz-se em repetições de padrões inerentes ao gênero, como a adjetivação hiperbólica em busca de equilíbrio frasal, recorrência de termos e versos inteiros e até mesmo o neologismo (VALENÇA, 1983)

A evolução do gênero levou a uma elaboração maior de letra e melodia capazes de suprir demandas populares, comerciais e de julgamento. Como vimos, essas modificações intrínsecas a padrões mutáveis levaram a um significativo aumento da quantidade de rimas encontradas nas composições com o passar dos anos. 
Dessa maneira, podemos observar a maior presença de rimas internas nos versos e sequências de rimas de mesma terminação em aumento gradual. Podemos citar, como ilustração desses casos, o samba enredo da Estação Primeira de Mangueira de zoı (AILTON; CESINHA; XAVIER; TE; BAIANO, 2010). Em passagens da obra o fenômeno mostra-se claramente perceptível, como no verso "Traço o meu passo no compasso", que apresenta uma sequência de rimas que variam em tipo dentro de uma mesma frase.

O samba enredo da Unidos da Tijuca para o carnaval de 2004 também nos revela bastante acerca das tendências mais modernas para padrões de rimas:

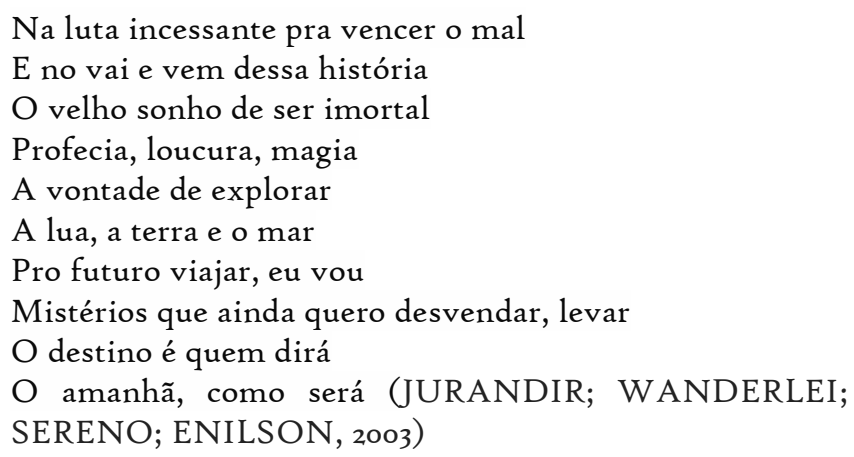

Nesse trecho verifica-se claramente o uso de rimas ricas e pobres de maneira intercalada, porém, principalmente, o uso das mesmas para a estruturação principal dos versos, como no caso de 'Profecia, loucura, magia' e 'Mistérios que ainda quero desvendar, levar'. Notória também é a repetição de palavras terminadas em 'ar' ou com sons próximos, são elas: explorar, mar, viajar, desvendar, levar, dirá e será. Tal recorrência, apesar de prática comum, é ainda atualmente bastante criticada e despontuada pelos jurados dos desfiles oficiais.

$\mathrm{Na}$ apuração do carnaval de 20II, por exemplo, verificou-se essa exigência de maneira clara. Apenas a Estação Primeira de Mangueira gabaritou o quesito samba enredo. As demais agremiações perderam preciosos décimos, tendo os jurados justificado as penalidades pela 'falta de criatividade'. A jurada Marta Macedo, ao avaliar as obras que cruzaram a Marquês de Sapucaí registrou em suas justificativas as i8 ocorrências de verbos terminados em 'ar' no samba da União da Ilha do Governador, is na obra da Imperatriz Leopoldinense e io na composição portelense. Em outro samba criticado, da Beija Flor, a jurada apontou a ocorrência de ıo rimas com terminação 'ão' ou 'ões' (LEMOS, 20II). 
A Acadêmicos do Grande Rio, em 2009, apresentou-se com um samba enredo marcado por essas nuances. A obra possui uma gama de repetições de rimas, como pode-se ver abaixo:

\author{
O rei sol bordado em ouro e a corte... A brilhar \\ Champagne, um baile pra comemorar \\ Mistérios da Terra Brasilis vão se revelar \\ Navegando não imaginava encontrar \\ Ver tanta beleza seduzindo o meu olhar \\ (DERÉ; DIAS; RIBEIRO; MINGAU, 2008)
}

Nos primeiros cinco versos da obra observamos a finalização dos versos com palavras terminadas em 'ar', dentre as quais quatro verbos. Na segunda parte observamos uma sequência, agora de quatro versos, de rimas finalizadas em 'ão', sendo, neste caso, todas presentes em substantivos:

\author{
O grande cabaré, na Cidade Luz \\ Sonho ou ilusão que me conduz \\ De um "passo", fiz um traço no compasso da paixão \\ É o vôo da evolução \\ Flores pra nação que sempre estendeu a mão \\ É festa, carnaval é união. \\ (DERÉ; DIAS; RIBEIRO; MINGAU, 2008)
}

Interessante notarmos que o terceiro verso do trecho acima destacado segue de forma exata o mesmo padrão do samba mangueirense de 20II, ao alocar em um mesmo verso os vocábulos 'traço', 'passo' e 'compasso'. Curiosamente, o samba enredo da Acadêmicos do Grande Rio de 2009 recebeu três notas Io.o e apenas uma nota 9.8, apesar dos 9 versos finalizados em 'ar'e dos 7 finalizados em ‘ão' (GLOBO, 2009). Esse fato evidencia a subjetividade com a qual o quesito samba enredo é julgado no carnaval de maneira geral, muitas vezes tendo como critério principal o gosto pessoal, em detrimento de uma análise técnica de fato.

Em contrapartida, no carnaval de 2020, a Paraíso do Tuiuti se apresentou com o enredo ' $\mathrm{O}$ Santo e o Rei: Encantarias de Sebastião', do carnavalesco João Vitor Araújo. O samba, dos renomados compositores Moacyr Luz, Cláudio Russo, Aníbal, Júlio Alves, Pier e Tricolor, sofreu duras críticas por parte do júri, o que acarretou a perda de décimos importantes durante a apuração. As inconsistências das rimas foram as justificativas mais recorrentes para as notas baixas, problema que para os julgadores enfraqueceu a riqueza poética da obra. Mais uma vez, o excesso de terminações repetitivas das rimas, nesse caso 'ado', foi um dos motivos para as punições (AMÂNCIO, 2020). 
Outro padrão amplamente observado são os denominados refrões de pergunta e resposta, ou responsoriais, utilizados largamente desde meados da década de 199o. Esse fenômeno, influenciado em grande parte pelo enorme sucesso alcançado pelo samba enredo do Acadêmicos do Salgueiro de 1993, consiste em:

I) apresentação de uma frase musical composta por dois membros; pergunta (o maior deles) e resposta (sempre de curta duração). Estes são separados por pausa ou nota de longa duração pertencente à pergunta;

2) uma pergunta ou duas repetições variadas dessa frase;

3) frase intermediária (em alguns casos) frequentemente sugerindo o elemento responsorial;

4) frase conclusiva (resolução) (PRADO, 2015, p. 179-18o)

Esses casos recorrentes por diversas vezes se valem de recursos e palavras bastante repetitivos, culminando em rimas, que apesar de possivelmente ricas, não refletem beleza ou complexidade poética, como, por exemplo, a dupla frequente 'eu vou / amor', bastante presentes nos membros denominados acima como resposta. São exemplos da situação descrita, elencados por Prado (2015, p. 182): 'Oi no balanço das ondas, eu vou / No mar eu jogo a saudade, amor' do Acadêmicos do Salgueiro em 1993 (CHAGAS; ARIZÃO; TRINDADE; BALA; GUARACY; QUINHO, 1992), 'Vamos acender a luz, é pra já / Vida de maracutaia, não, não dá' da Unidos do Porto da Pedra de 1998 (DO IMPÉRIO; TELLES; ROBERTO; DODI, 1997) e 'Tem pierrot e colombina, amor / O circo encanta e me fascina, chegou' da Acadêmicos de Santa Cruz 2003 (DOUTOR; DE LIMA; PENTEADO; CHARUTO; BOMBEIRO, 2002).

Em outras composições observamos os refrões responsoriais com repetição do mesmo vocábulo em dois versos distintos. É o caso da capixaba Independente de Boa Vista, que em 2014 desfilou com o seguinte refrão:

Quem é que espalha o perfume no ar?

Sou eu

Quem é que faz o meu povo sambar?

Sou eu, sou eu

É a boa vista, o meu grande amor

A essência do samba chegou (DO CAVACO; RIGOLON; EMERSON; MYNGAL, 2013)

Interessante notar que ambas as respostas encontradas nos dois primeiros versos baseiam-se na mesma construção: 'Sou eu'. 
Se por um lado alguns pecam pelo excesso, a maior dificuldade na composição sem rimas é evidenciada pela quantidade de sambas que não apresentam esse recurso poético. Em nosso universo de estudo, apenas o supracitado samba da Unidos de Vila Isabel de 1987 não apresenta qualquer espécie de rima, mesmo assim não configurando uma ocorrência ao acaso, uma vez que a obra foi propositalmente concebida dessa maneira. É o caso também dos sambas do Acadêmicos do Sossego de 2016 e 2019, que não fizeram parte deste estudo por pertencerem a diferentes grupos do carnaval carioca.

De maneira geral, a popularização dos recursos abordados contribuiu fortemente para o aumento do número de rimas por verso nos sambas de enredo, uma vez que levaram o compositor a soluções semelhantes e construções confortáveis tanto em letra quanto em melodia.

\section{CONCLUSÃO}

A análise das letras dos 683 sambas enredo do grupo especial do Rio de Janeiro nos mostrou de maneira clara o aumento linear e consistente do número de rimas por verso nas composições entre as décadas de 1970 e 2010. Essa informação será capaz de auxiliar nos estudos futuros acerca da evolução do gênero e na compreensão do processo constante pelo qual o mesmo passa.

Como elucidado no corpo do trabalho, o aumento da ocorrência de rimas não possui ligação direta com critérios de qualidade, porém, esse fenômeno decorre também diretamente dos mesmos processos de mutação e adaptação que moldaram o samba enredo nas últimas cinco décadas, como a necessidade de popularização, canto fácil, métrica de rápida assimilação e andamento acelerado. Somado a isso, percebemos que um alto fator de rimas por verso não pode ser traduzido integralmente em riqueza poética ou beleza. Muitas vezes esse alto fator é decorrente de repetições de rimas, excesso de rimas pobres e recorrência de padrões frasais. Esses recursos, muitas vezes populares e, por que não, popularizantes, repetidamente esbarram em critérios subjetivos de avaliação e concessão de notas.

A rima pode ter se tornado um acessório indispensável ao compositor moderno, um dos catalisadores poéticos capazes de conduzi-lo ao lugar comum, facilitar o ajuste da letra à melodia e criar sambas cada vez mais pasteurizados. 


\section{REFERÊNCIAS}

AILTON; CESINHA; XAVIER, Alemão; TE; BAIANO. O filho fiel, sempre Mangueira. In LUIZITO; SIERRA, Zé Paulo; CIGANEREY. Sambas de enredo 20rr. Rio de Janeiro: Universal Music, 2010. I CD. Faixa 5.

AMANCIO, Victor. Julgadores de samba-enredo apontaram problemas na melodia e nas rimas do Tuiuti. Carnavalesco. Disponível em: <hwww.carnavalesco.com.br/julgadores-de-samba-enredoapontaram-problemas-na-melodia-e-nas-rimas-do-tuiuti/>. Acesso em: 23 jan. 2020.

CHAGAS, Demá; ARIZÃO; TRINDADE, Celso; BALA; GUARACY; QUINHO. Peguei um Ita no Norte. In MARQUES, Melquisedeque. Sambas de enredo das escolas de samba do Grupo Especial - Carnaval 1993. Rio de Janeiro: BMG-Ariola, 1992. I disco sonoro. Lado B, faixa 8.

DA VILA, Martinho; BESSA, Ovídio; AZO. Raízes. In DA VILA, Martinho; GERA. Sambas de enredo das escolas de samba do grupo IA - Carnaval 1987. Rio de Janeiro: RCA Victor, 1986. I disco sonoro. Lado B, faixa II.

DERÉ; DIAS, Emerson; RIBEIRO, Rafael; MINGAU. Voilá, Caxias! Para sempre liberté, egalité, fraternité. Merci beaucoup, Brésil! Não tem de quê!. In WANTUIR. Sambas de enredo 2009. Rio de Janeiro: Universal Music, 2008. I CD. Faixa 3.

DO CAVACO, Bid; RIGOLON, Chanel; EMERSON; MYNGAL, Sidney. Teu cheiro me dá 289 prazer... Boa Vista espalha o perfume no ar. Disponível em: <www.letras.mus.br/sambas/independente-de-boa-vista-samba-enredo-2014/> Acesso em 23 jan. 2020.

DO IMPÉRIO, Índio; TELLES, Tião; ROBERTO, Paulo; DODI, Jorge. Samba no pé e mãos ao alto, isto é um assalto. In WANTUIR. Sambas de enredo '98. Rio de Janeiro: BMG Brasil, 1997. I CD. Faixa 5.

DOUTOR; DE LIMA, Fernando; PENTEADO, Eli; CHARUTO; BOMBEIRO, Marquinho. In ANDANÇAS, Luizinho. Samba de enredo 2003. Rio de Janeiro: BMG, 2002. I CD. Faixa i4.

FARIAS, Julio Cesar. O samba enredo e o ensino da língua portuguesa e da literatura. Revista Interfaces, Rio de Janeiro, v. 2, n. II, p. 73-8o, dez. 2007.

FERRARI, Bruno. A perda no tom épico do samba-enredo carioca no século XXI. Revista Épicas. Sergipe, v. I, n. I, p. 132-I47, jun. 2017.

GLOBO, Carnaval 2009. Disponível em: <gi.globo.com/carnaval2009/o,,mul99866i-16634,ooconfira+as+notas+da+apuracao+no+rio.html $>$. Acesso em: 23 jan. 2020. 
HENRIQUE, Antonio. O samba-enredo e as suas mais recentes transformações: entre crises e polêmicas. In NEDER, Álvaro. Leituras sobre música popular: reflexões sobre sonoridades e cultura. Rio de Janeiro. UFRJ, PPGSA, 2008. p. 49-74.

JURANDIR; WANDERLEI; SERENO; ENILSON. O sonho da criação e a criação do sonho. A arte da ciência no tempo do impossível. In WANTUIR. Sambas de enredo 2004. Rio de Janeiro: BMG. I CD. Faixa 9.

LEMOS, Rafael. Sapucaí, túmulo do samba. Veja Online. Disponível em: <veja.abril.com.br/cultura/sapucai-tumulo-do-samba/>. Acesso em: 23 jan. 2020.

LIESA - Liga Independente das Escolas de Samba do Rio de Janeiro. Manual do julgador. Rio de Janeiro, 2020.

PIGNATARI, Décio; O que é comunicação poética. 8ํㅡㄹ Edição. Cotia, SP. Ateliê Editorial, 2005.

PRADO, Yuri. Padrões musicais do samba-enredo na era do Sambódromo. Música em perspectiva, Paraná, v. 8, n. I, p. 155-196, jun. 2015.

RIOTUR. Memória do Carnaval. Rio de Janeiro, 1991.

VALENCA, Raquel. Palavras de purpurina. Estudo linguístico do samba de enredo, 1983. 300 p. 290 Dissertação (Mestrado em Letras) - Instituto de Letras, Universidade Federal Fluminense, Niterói, 1983. 